\title{
Yttrium-90 radioembolization of hepatic metastases from colorectal cancer
}

\author{
Mihir Raval ${ }^{1}$, Dinesh Bande ${ }^{2,3,4}$, Anil K. Pillai ${ }^{5,6}$, Lawrence S. Blaszkowsky ${ }^{7,8,9}$, Suvranu Ganguli ${ }^{710,11,}$ \\ Muhammad S. Beg ${ }^{5,12}$ and Sanjeeva P. Kalva ${ }^{5,6 *}$ \\ 1 Department of Hospital Medicine, Essentia Health, Fargo, ND, USA \\ 2 Department of Hospital Medicine, Sanford Health, Fargo, ND, USA \\ ${ }^{3}$ Roger Maris Cancer Center, Fargo, ND, USA \\ ${ }^{4}$ Department of Internal Medicine, University of North Dakota, Fargo, ND, USA \\ ${ }^{5}$ Harold Simmons Cancer Center, University of Texas Southwestern Medical Center, Dallas, TX, USA \\ ${ }^{6}$ Interventional Radiology, University of Texas Southwestern Medical Center, Dallas, TX, USA \\ ${ }^{7}$ Massachusetts General Hospital Cancer Center, Boston, MA, USA \\ ${ }^{8}$ Department of Hematology and Oncology, Massachusetts General Hospital, Boston, MA, USA \\ ${ }^{9}$ Department of Medicine, Harvard Medical School, Boston, MA, USA \\ ${ }^{10}$ Section of Interventional Radiology, Department of Imaging, Massachusetts General Hospital, Boston, MA, USA \\ $"$ Department of Radiology, Harvard Medical School, Boston, MA, USA \\ 12 Division of Hematology and Oncology, Department of Medicine, University of Texas Southwestern Medical Center, Dallas, TX, USA
}

Edited by:

Kathy Willowson, University of Sydney, Australia

Reviewed by:

Athanasios Zafeirakis, 401 Army

Hospital of Athens, Greece

Mustafa Erkan Altinyay, National

Guard Health Affairs, Saudi Arabia

${ }^{*}$ Correspondence:

Sanjeeva P. Kalva, Interventional

Radiology, University of Texas

Southwestern Medical Center, 5323

Harry Hines BIvd, Dallas, TX

75390-8834, USA

e-mail:sanjeeva.kalva@

utsouthwestern.edu
Liver metastases from colorectal cancer (CRC) result in substantial morbidity and mortality. The primary treatment is systemic chemotherapy, and in selected patients, surgical resection; however, for patients who are not surgical candidates and/or fail systemic chemotherapy, liver-directed therapies are increasingly being utilized. Yttrium-90 (Y-90) microsphere therapy, also known as selective internal radiation therapy (SIRT) or radioembolization, has proven to be effective in terms of extending time to progression of disease and also providing survival benefit. This review focuses on the use of Y-90 microsphere therapy in the treatment of liver metastases from CRC, including a comprehensive review of published clinical trials and prospective studies conducted thus far. We review the methodology, outcomes, and side effects of Y-90 microsphere therapy for metastatic CRC.

Keywords: colorectal cancer, liver metastases, radioembolization, Yttrium-90 microspheres, Y-90 therapy, selective internal radiation therapy

\section{INTRODUCTION}

The liver is the most common site of metastases from colorectal cancer (CRC). Approximately $20 \%$ of patients are found to have distant metastases at the time of CRC diagnosis with approximately $40 \%$ to the liver $(1,2)$. An additional $35-60 \%$ of patients develop liver metastases in the course of the disease. Presence of liver metastases portends a poor prognosis. Of the patients who develop liver metastases, one-fifth dies with liver metastases only. In the absence of treatment, the median survival is approximately $4-6$ months. Surgical resection of liver metastases provides the best 5 -year survival, in the order of $40 \%$, and is possible if the disease is localized or downgraded with systemic chemotherapy and a safe surgical margin can be achieved without significant post-operative liver dysfunction (35). Only $10-20 \%$ of patients who present with liver metastases from CRC are surgical candidates $(2-5)$. The role of standard external beam radiation has been limited due to poor tolerance of the normal liver tissue to radiation. As such, palliative chemotherapy had for many years been the only option for the majority of patients with liver metastases from CRC. The fluropyrimidine 5-fluorouracil has been used in the management for several decades. The introduction of several new cytotoxic agents, including oxaliplatin, irinotecan, and targeted therapies including VEGF and EGFR inhibitors, has resulted in substantial improvement in median survival, which now exceeds 2 years (6-9).

Since the majority of CRC metastases occur in the liver and the benefit from systemic chemotherapy has been modest until recently, selective hepatic arterial chemotherapy through arterial infusion of 5-fluorouracil has been practiced with mixed results $(10,11)$. Such therapy is based on the principle that the metastases receive the majority of blood flow from the hepatic artery (12) and direct arterial infusion of chemotherapeutic drugs would result in higher tumoral concentration of the drugs compared to those achieved with intravenous administration due to high first pass hepatic extraction of the drugs (13). New regimens of systemic chemotherapy have virtually replaced hepatic artery infusion chemotherapy due to better results (6). However, there has been resurgence of hepatic artery directed therapies through the use of microparticles that either carries radiation (radioembolization) or chemotherapeutic drugs (chemoembolization) (14). In this article, we present the rationale, treatment aspects, and results of radioembolization in the treatment of hepatic colorectal metastases. 


\section{RATIONALE OF RADIOEMBOLIZATION THERAPY}

Radioembolization with Yttrium-90 (Y-90) microspheres is based on the same principle as that of hepatic artery infusion chemotherapy. The hepatic artery provides the primary vascular supply to the tumor with $>80 \%$ of the blood flow to the tumor being derived from the hepatic artery whereas the normal liver parenchyma receives the majority of its blood flow via the portal vein (12). In addition, the microvascular density of the hepatic tumors is 3-200 times higher than the surrounding normal liver parenchyma (15) leading to a higher localized entrapment of microparticles in the tumor when the microparticles are infused through the hepatic artery. CRC cells are highly radiosensitive and do not demonstrate any cross-resistance to radiation despite being chemotherapy-refractory. Additionally, radiation works synergistically when used with radiationsensitizing chemotherapeutic drugs. Unlike external beam radiation, which is limited to treatment of small number of focal tumors due to concerns of liver toxicity with multi-focal disease, selective infusion of Y-90 microspheres allows selective "inside-out" radiation of multi-focal tumors through selective localization of the particles in the tumor vessels and localized emission of beta radiation in the tumor environment (14). Because of this, Y-90 radioembolization is also known as "selective internal radiation therapy" (SIRT) or intra-arterial brachytherapy.

\section{YTTRIUM-90 MICROSPHERES}

The first intra-arterial infusion of Y-90 radio-isotope for treatment of pancreatic and primary liver cancer was reported in 1965 (16). Since that time, there have been significant advances in the production, distribution, and administration of these microspheres. Currently, there are two commercially available Y-90 labeled microsphere preparations - TheraSpheres (BTG International Canada Inc, Ottawa, ON, Canada) and SIR-spheres (Sirtex Medical Inc., Sydney, NSW, Australia). Both microspheres measure $20-60 \mu \mathrm{m}$ in size (TheraSpheres $20-30 \mu \mathrm{m}$ and SIR-spheres, $20-60 \mu \mathrm{m}$ ), and are designed to carry Y-90. Y-90 is a beta radiation emitter, with a half-life of $64.1 \mathrm{~h}$ and an average energy of $0.94 \mathrm{MeV}$. The radiation has a range of $1.1 \mathrm{~cm}$ (average $2.5 \mathrm{~mm}$ in the tissues) from the source, and $94 \%$ of the dose is delivered within the first 11 days following administration (14). The microspheres remain embedded in the vascular bed permanently without undergoing any physical or chemical change. The major differences between the two preparations are the density and specific activity (radiation dose per microsphere) of the particles, and their FDA approval $(17,18)$. TheraSpheres are made of glass and Y-90 is embedded within the glass matrix leading to higher density and specific activity $(2500 \mathrm{~Bq})$ of the preparation. SIRspheres are made of resin and Y-90 is coated on the surface of the particle leading to low density and low specific activity (50 Bq). The FDA approved TheraSpheres under the category of humanitarian device exemption for use in patients with unresectable hepatocellular carcinoma requiring on site institutional review board (IRB) oversight. SIR-spheres received FDA approval in 2002 as a brachytherapy device for treatment of unresectable hepatic metastases from CRC with adjuvant hepatic artery infusion of floxuridine.

\section{ADMINISTRATION OF YTTRIUM-90 MICROSPHERES}

A successful intra-tumoral administration of Y-90 microspheres involves careful patient selection, assessment of the hepatic arteries and hepato-pulmonary shunt, dose calculation, and intra-arterial delivery of the microspheres.

\section{PATIENT SELECTION}

Careful evaluation for optimal patient selection is required to optimize the outcomes and limit toxicities of Y-90 radioembolization. The recommended selection criteria are listed in Table 1 (19). Patients with poor performance status, limited hepatic reserve, and extensive multi-organ metastases are poor candidates for this therapy. At many centers, baseline evaluation is performed with PET-CT to detect extra-hepatic disease and to assess the volume and biological activity of the tumor.

\section{ASSESSMENT OF HEPATIC ARTERIES AND HEPATO-PULMONARY SHUNT}

Selective intra-arterial infusion of Y-90 microspheres requires careful angiographic evaluation of the hepatic arteries to plan for lobar or segmental delivery of the microspheres, to isolate hepatic perfusion to a few arteries (so as to minimize the number of infusions or to minimize risks of extra-hepatic delivery) and to pro-actively exclude the hepatic artery branches (such as the gastric or duodenal arteries) that are at risk of non-targeted delivery of the microspheres. The hepatic arterial branches that are at risk of non-target delivery are occluded (embolized) with coils.

The hepato-pulmonary shunt can lead to non-target deposition of Y-90 microspheres in the lung. Some of the microspheres escape the liver through large ( $>30 \mu \mathrm{m}$ in diameter) intra-tumoral arteriovenous shunts and get entrapped in the pulmonary capillaries. The degree of shunting is estimated through intra-arterial infusion of Tc-99 m macro-aggregated albumin (4-5 mCi) and subsequent measurement of the lung and liver activity on a gamma camera. Presence of hepato-pulmonary shunt per se is not a contra-indication for treatment with Y-90 microspheres as long as the radiation dose per treatment to the lung does not exceed $30 \mathrm{~Gy}$ or the cumulative dose to the lungs is within $50 \mathrm{~Gy}$.

\section{DOSE CALCULATION}

Dose calculation is based on the tumor volume in the liver (20). Two methods popularly used include the empiric method and the body surface area (BSA) method. In the empiric method, $2 \mathrm{GBq}$ of Y-90 dose is given for a tumor volume occupying $<25 \%$ of the liver, $3 \mathrm{GBq}$ if the tumor volume is $25-50 \%$ of the liver volume, and $5 \mathrm{GBq}$ if the tumor volume exceeds $>50 \%$ of the liver volume. BSA method takes in to consideration of the BSA, liver volume, and tumor volume and is tailored to the patient and the volume of the liver treated. The calculated dose in gigabecquerel is $[(\mathrm{BSA}-0.2)+\{$ Tumor volume/(Tumor volume + Liver volume)\}]. Many centers in the US follow BSA method for dose calculation $(19,21,22)$. Treatment based on the dose calculated by the empiric method (especially when the tumor volume exceeds $>25 \%$ ) results in very high, often fatal, radiation dose to the liver and is not recommended. The dose calculations for TheraSpheres are based on partition model with an intent to deliver 80-120 Gy of radiation dose to the treated volume of the liver. 
Table 1 | Patient selection criteria for Yttrium-90 radioembolization of hepatic metastases from colorectal cancer

\section{TUMOR SPECIFIC}

Liver metastases not eligible for surgery or local ablative therapy

Failed first line systemic chemotherapy (unless planning for concomitant systemic chemotherapy)

No significant hepato-pulmonary shunt (which results from presence of large intra-tumoral arteriovenous shunts). Radioembolization is not performed if the radiation dose to the lung exceeds $30 \mathrm{~Gy}$ per treatment

Absent or minimal extra-hepatic metastases

\section{LIVER SPECIFIC}

Relatively preserved liver and kidney function - serum bilirubin $<2 \mathrm{mg} / \mathrm{dL}$, serum creatinine $<1.8 \mathrm{mg} / \mathrm{dL}$; platelet count $>50,000 / \mu \mathrm{L}$

Preserved hepatopetal flow in the main portal vein

No risk of non-target delivery of the microspheres during hepatic arterial infusion

No prior radiation to the liver

\section{PATIENT SPECIFIC}

ECOG performance status of 2 or less

Life expectancy of $>6$ weeks
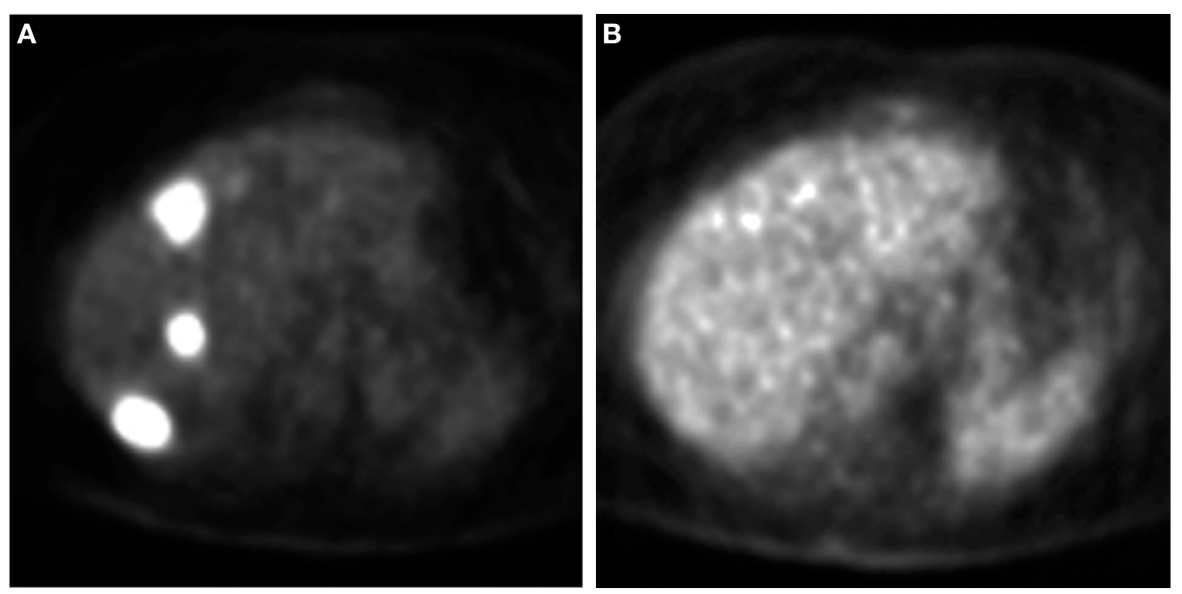

FIGURE 1 | Assessment of response to Y-90 therapy on PET. A PET scan (A) obtained prior to Y-90 therapy demonstrates three FDG avid lesions. A repeat PET scan (B) obtained 6 weeks after Y-90 therapy shows no FDG avid lesions suggesting complete metabolic response.

\section{INFUSION OF YTTRIUM-90 MICROSPHERES}

Selective infusion of Y-90 microspheres is achieved through closed circuit delivery using proprietary delivery device that is specific for each company. Both lobar and whole liver infusions are practiced; authors prefer to use lobar or segmental infusions over whole liver infusions in order to limit hepatic toxicities. Post infusion imaging of the liver through SPECT or PET is often performed (though not required) to assess the hepatic uptake pattern of the microspheres.

\section{PATIENT FOLLOW-UP AND SUBSEOUENT TREATMENTS}

When not contraindicated, some centers administer systemic 5fluorouracil before and after Y-90 therapy. Toxicities are assessed at 1 and 4 weeks following Y-90 therapy. In the presence of bilobar disease, Y-90 radioembolization of the other lobe is performed at 4-6 weeks from initial therapy. A follow-up PET-CT is performed at 6 weeks after second treatment. There are no standardized guidelines on timing of follow-up imaging studies to assess tumor response. PET has been shown to be useful in assessing response and guiding further treatment (Figure 1); the role of CT attenuation change of the tumor as a surrogate marker of response is currently being explored (Figure 2) (23-25). Subsequent imaging assessment is performed at 3 month intervals with PET-CT. Additional Y-90 infusions are performed (up to two treatments per lobe) if tumor recurs.

\section{TOXICITIES}

Most patients report fever, lethargy, decreased appetite, and fatigue following therapy. Uncommon serious adverse events include radiation-induced gastric ulcers, lymphocytopenia, jaundice, cholecystitis, lung toxicity, hepatic abscess, radiation hepatitis, and liver failure (26-29). Patients are advised to take proton pump inhibitors to prevent gastrointestinal side effects. Use of periprocedural steroids to prevent development of fatigue or chronic liver injury is also described (29). The hepatic injury from Y-90 appears to be secondary to development of portal triaditis (29).

\section{OUTCOMES}

Given that Y-90 radioembolization for hepatic colorectal metastases has been used at various stages of the disease and with or without systemic or regional chemotherapy, the outcomes of this 


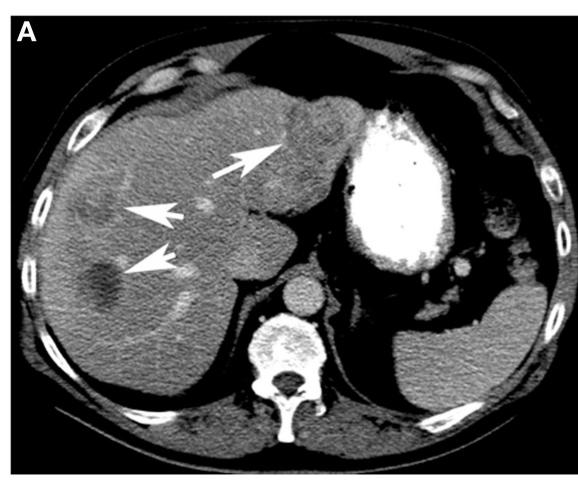

FIGURE 2 | Assessment of response to Y-90 therapy on CT. A contrast enhanced CT scan (A) of the liver demonstrates hypo-attenuating lesions (arrows) in the liver. A repeat contrast enhanced CT scan (B) obtained 6 weeks

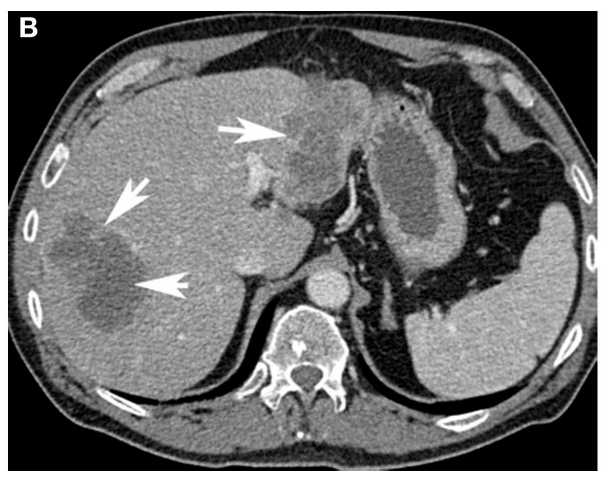

after Y-90 therapy shows very low attenuation of the lesions (arrows). Even though the lesions size has not significantly changed, the development of very low attenuation on post-treatment scan suggests response to Y-90 therapy.

Table 2 |Yttrium-90 radioembolization as first line therapy for hepatic colorectal metastases.

\begin{tabular}{|c|c|c|c|c|c|c|}
\hline Author & No. of patients & Trial design & Treatment & Response & Survival & Complications \\
\hline $\begin{array}{l}\text { Gray et al. } \\
(30)\end{array}$ & $\begin{array}{l}74 \text { (only } 70 \\
\text { included in } \\
\text { analysis) }\end{array}$ & $\begin{array}{l}\text { Prospective, phase } \\
\text { III, randomized }\end{array}$ & $\begin{array}{l}\text { Y-90 radioembolization } \\
\text { plus hepatic arterial } \\
\text { chemoinfusion (HAC) } \\
\text { with floxuridine ( } n=36 \text { ) } \\
\text { vs. HAC with floxuridine } \\
(n=34)\end{array}$ & $\begin{array}{l}\text { Response } \\
(\mathrm{CR}+\mathrm{PR}): 44 \\
\text { vs. } 17.6 \% \\
(p=0.001) \\
\text { response } \\
\text { (CEA): } 72 \text { vs. } \\
47 \% \\
(p=0.004)\end{array}$ & $\begin{array}{l}\text { TTP: } 15.9 \text { vs. } 9.7 \mathrm{~m} \\
\text { ( } p=0.001) ; 1,2,3, \text { and } \\
5 \text { year survivals: } 72,39, \\
17,3.5 \text { vs. } 68,29,6.5, \\
\text { and } 0 \% \text {; median } \\
\text { survival: } 17 \text { vs. } 15.9 \mathrm{~m} \\
\text { ( } p=0.18)\end{array}$ & $\begin{array}{l}\text { Higher incidence of grade } 3 \\
\text { elevation of alkaline } \\
\text { phosphatase in the group that } \\
\text { received Y-90 plus HAC; no } \\
\text { overall difference in the } \\
\text { incidence of grade } 3-4 \\
\text { toxicities among the two } \\
\text { groups }\end{array}$ \\
\hline
\end{tabular}

\begin{tabular}{|c|c|c|c|c|c|c|}
\hline $\begin{array}{l}\text { Van Hazel } \\
\text { et al. (31) }\end{array}$ & 21 & $\begin{array}{l}\text { Prospective, phase } \\
\text { II, randomized }\end{array}$ & $\begin{array}{l}\text { Y-90 radioembolization } \\
\text { plus systemic } \\
\text { 5-fluorouracil and } \\
\text { leucovorin }(n=11) \text { vs. } \\
\text { systemic } 5 \text {-fluorouracil } \\
\text { and leucovorin ( } n=10 \text { ) }\end{array}$ & $\begin{array}{l}\text { Best } \\
\text { confirmed } \\
\text { response: } \\
\text { 8PR, 3SD vs. } \\
\text { OPR, 6SD, 4PD } \\
(p<0.001)\end{array}$ & $\begin{array}{l}\text { Median survival: } 29.4 \\
\text { vs. } 12.8 \mathrm{~m}(p=0.02) \\
\text { PFS: } 18.6 \text { vs. } 3.4 \mathrm{~m}\end{array}$ & $\begin{array}{l}\text { Grade } 3 \text { and } 4 \text { toxicity events: } \\
13 \text { vs. } 5 \text {; No difference in } \\
\text { quality of life }\end{array}$ \\
\hline $\begin{array}{l}\text { Sharma } \\
\text { et al. (32) }\end{array}$ & 20 & $\begin{array}{l}\text { Prospective, single } \\
\text { arm; patients with } \\
\text { unresectable } \\
\text { disease and } \\
\text { chemo-naive }\end{array}$ & $\begin{array}{l}\text { Y-90 radioembolization } \\
\text { plus FOLFOX }\end{array}$ & 18PR, 2SD & $\begin{array}{l}\text { TTP: } 12.3 \mathrm{~m} \text { in patients } \\
\text { with EHD, } 14.2 \mathrm{~m} \text { in } \\
\text { patients without EHD. } \\
\text { Median PFS: } \\
9.3 \text { months }\end{array}$ & $\begin{array}{l}\text { Grade } 3-4 \text { neutropenia in } 12 . \\
\text { Gastric ulcer in } 1 . \text { Grade } 3 \\
\text { hepatotoxicity in } 1\end{array}$ \\
\hline $\begin{array}{l}\text { Kosmider } \\
\text { et al. (33) }\end{array}$ & 19 & Retrospective & $\begin{array}{l}\text { Y-90 radioembolization } \\
\text { plus 5-fluorouracil and } \\
\text { leucovorin }(n=7) \text { or } \\
\text { FOLFOX }(n=12)\end{array}$ & $\begin{array}{l}\text { ORR: } 84 \% \\
\text { (2CR, 14PR) }\end{array}$ & $\begin{array}{l}\text { PFS: } 10.4 \mathrm{~m} \text {; OS: } \\
29.4 \mathrm{~m} \text {; significantly } \\
\text { better survival if no } \\
\text { EHD (37.8 vs. } 13.4 \mathrm{~m} \text { ) }\end{array}$ & $\begin{array}{l}\text { Febrile neutropenia with } \\
\text { concurrent FOLFOX } \\
\text { treatment, a perforated } \\
\text { duodenal ulcer, and one death } \\
\text { from hepatic toxicity }\end{array}$ \\
\hline
\end{tabular}

CR, complete response; $P R$, partial response; SD, stable disease; $P D$, progressive disease; PFS, progression free survival; EHD, extra-hepatic disease; ORR, objective response rate; OS, overall survival; CEA, carcinoembryonic antigen; TTP, time to progression; HAC, hepatic arterial chemoinfusion.

therapy are described in this manuscript according to the timing of this therapy and systemic chemotherapy.

\section{YTTRIUM-90 RADIOEMBOLIZATION AS FIRST LINE THERAPY}

The first prospective study that led to FDA registration of Y-90 microspheres (SIR-spheres) for treatment of hepatic metastases from CRC included 74 patients who were randomized to receive hepatic arterial chemoinfusion (HAC) of floxuridine and single whole liver Y-90 therapy through hepatic artery access port or HAC of floxuridine alone (Table 2) (30). The final analysis included 70 patients. There was significantly higher objective response rate in patients who received Y-90 microsphere therapy in addition 
Table 3 | Yttrium-90 radioembolization in combination with second- or third-line chemotherapy.

\begin{tabular}{|c|c|c|c|c|c|c|}
\hline Author & No. of patients & Trial design & Treatment & Response & Survival & Complications \\
\hline $\begin{array}{l}\text { Van Hazel } \\
\text { et al. (34) }\end{array}$ & 25 & $\begin{array}{l}\text { Prospective, dose } \\
\text { escalation study }\end{array}$ & $\begin{array}{l}\text { Irinotecan at } 50,75 \text {, } \\
\text { or } 100 \mathrm{mg} / \mathrm{m}^{2} \text { on } \\
\text { days } 1 \text { and } 8 \text { of a } \\
\text { 3-week cycle for the } \\
\text { first two cycles, and } \\
\text { full irinotecan doses } \\
\text { (i.e., } 100 \mathrm{mg} / \mathrm{m}^{2} \text { ) } \\
\text { during cycles 3-9. } \\
\text { Radioembolization } \\
\text { during the first } \\
\text { chemotherapy cycle }\end{array}$ & $\begin{array}{l}\mathrm{PR} \text { in } 11(48 \%) \text { of } \\
23, \text { and } \mathrm{SD} \text { in } 9 \\
(39 \%)\end{array}$ & $\begin{array}{l}\text { Median PFS: } \\
6.0 \text { months; } \\
\text { Median OS: } \\
12.2 \text { months }\end{array}$ & $\begin{array}{l}\text { Grades } 3-4 \text { events in three of six } \\
\text { patients at } 50 \mathrm{mg} / \mathrm{m}^{2} \text { (obstructive } \\
\text { jaundice, thrombocytopenia, and } \\
\text { diarrhea), in five of } 13 \text { patients at } \\
75 \mathrm{mg} / \mathrm{m}^{2} \text { (neutropenia, leukopenia, } \\
\text { thrombocytopenia, elevated alkaline } \\
\text { phosphatase, abdominal pain, ascites, } \\
\text { and fatigue) and in four of six patients } \\
\text { at } 100 \mathrm{mg} / \mathrm{m}^{2} \text { (diarrhea, deep vein } \\
\text { thrombosis, constipation, and } \\
\text { leukopenia) }\end{array}$ \\
\hline $\begin{array}{l}\text { Lim et al. } \\
\text { (35) }\end{array}$ & 30 & $\begin{array}{l}\text { Prospective; all } \\
\text { patients who } \\
\text { failed initial 5-FU } \\
\text { chemotherapy, } 22 \\
\text { failed oxaliplatin } \\
\text { or irinotecan also. } \\
\text { EHD in } 7\end{array}$ & $\begin{array}{l}\text { Radioembolization; } \\
\text { concurrent 5FU in } 21\end{array}$ & $\begin{array}{l}\text { PR in } 10(33 \%) \text {; SD } \\
\text { in } 8(27 \%) \text {; no } \\
\text { response in } \\
\text { patients with poor } \\
\text { performance status } \\
\text { or with extra } \\
\text { hepatic disease }\end{array}$ & $\begin{array}{l}\text { TTP: } \\
5.3 \text { months }\end{array}$ & $\begin{array}{l}\text { Duodenal/gastric ulcer in } 13 \% . \text { One } \\
\text { death related to radiation hepatitis }\end{array}$ \\
\hline
\end{tabular}

$C R$, complete response; $P R$, partial response; $S D$, stable disease; $P D$, progressive disease; PFS, progression free survival; EHD, extra-hepatic disease; ORR, objective response rate; OS, overall survival; CEA, carcinoembryonic antigen; TTP, time to progression; HAC, hepatic arterial chemoinfusion.

to HAC compared to those who received HAC alone (Response rate based on WHO criteria at 3 months was 44.4 vs. $17.6 \%$, $p=0.01$ ) (30). More patients in the Y-90 group demonstrated $50 \%$ or more reduction in elevated CEA levels following therapy (72.2 vs. $47.1 \%, p=0.004)(30)$. The median time to tumor progression (TTP) was longer in the group that received Y-90 (15.9 vs. 9.7 months). Though a trend for a survival advantage in this group was observed, it did not reach statistical significance. Authors also reported 3.1 times (95\% CI: 1.1-8.8) higher risk of death from progression of liver metastases in patients who received HAC alone. There were no significant differences in the incidence of Grade 3 or 4 toxic events in either group. This study is significant in that it demonstrated safety of Y-90 therapy when combined with $\mathrm{HAC}$ of floxuridine and such addition definitively improved objective response rate and TTP in predominately chemo-naive patients. However, the study failed to demonstrate any significant survival advantage of such combination therapy. This may be due to the small number of patients enrolled in this study. Secondly, the study randomized patients to HAC with floxuridine, which is rarely used as first line therapy. The first line chemotherapy currently employed includes a combination of 5-fluorouracil, leucovorin plus oxaliplatin, or irinotecan (FOLFOX or FOLFIRI) with or without biological agents such as bevacizumab.

A subsequent phase 2 study by the same group addressed some of the issues related to the first study (31). Patients were randomized to receive systemic chemotherapy with 5-fluorouracil and leucovorin alone or in combination with a single hepatic artery infusion of Y-90 resin microspheres (Table 2). The results supported the fact that the addition of single infusion of Y-90 microspheres resulted in significantly higher objective response rate (ORR: 90.1 vs. $0 \%$; $p<0.001$ ), longer TTP (18.6 vs. 3.6 months; $p<0.0005)$, and better median survival (29.4 vs. 12.8 months; $p=0.025)$. This study was limited by the small patient cohort (total of 21 patients only) and use of 5-FU and leucovorin only for chemotherapy.

Sharma et al., in a phase 1 study, assessed the toxicity and maximum tolerated dose of oxaliplatin during the first three cycles of chemotherapy (FOLFOX) when used as a radiation sensitizer for Y-90 therapy that was administered within 3-4 days of first cycle of chemotherapy (Table 2) (32). Patients received standard dose oxaliplatin from the fourth cycle of chemotherapy (FOLFOX). Most of the patients with bilobar disease received sequential lobar infusion of Y-90 microspheres. The maximum tolerated dose was $60 \mathrm{mg} / \mathrm{m}^{2}$ of oxaliplatin for the first three cycles, with full dose FOLFOX thereafter. The toxicity was limited to grade 3 abdominal pain in five patients, Grade 3-4 neutropenia in 12 and one episode of Grade 3 hepatotoxicity. They reported a $90 \%$ partial response (PR) rate at 12 weeks, median progression free survival (PFS) of 9.3 months and TTP of 12.3 months. In patients with no extrahepatic disease, the PFS was 14.2 months. This study is significant in that it demonstrated the safety of combining Y-90 therapy with standard first line systemic chemotherapy (FOLFOX). Since it is a phase I study without randomization to a chemotherapy alone arm, it is difficult to draw conclusions on the effectiveness of such combination therapy. The median PFS and overall survival reported by the authors who applied FOLFOX regimen used as first line chemotherapy without Y-90 radioembolization range from 7.6 to 9.0 months and 16.2 to 19.5 months, respectively.

In a retrospective review, Kosmider et al. reported results of combination therapy with Y-90 microspheres and systemic chemotherapy with FOLFOX or 5-FU + leucovorin as first line therapy for hepatic metastases from colon cancer (Table 2) (33). The reported objective response rate was $84 \%$ with a median PFS of 10.4 months and median survival of 29.4 months. The median 
Table 4 | Yttrium-90 as salvage therapy for chemorefractory patients.

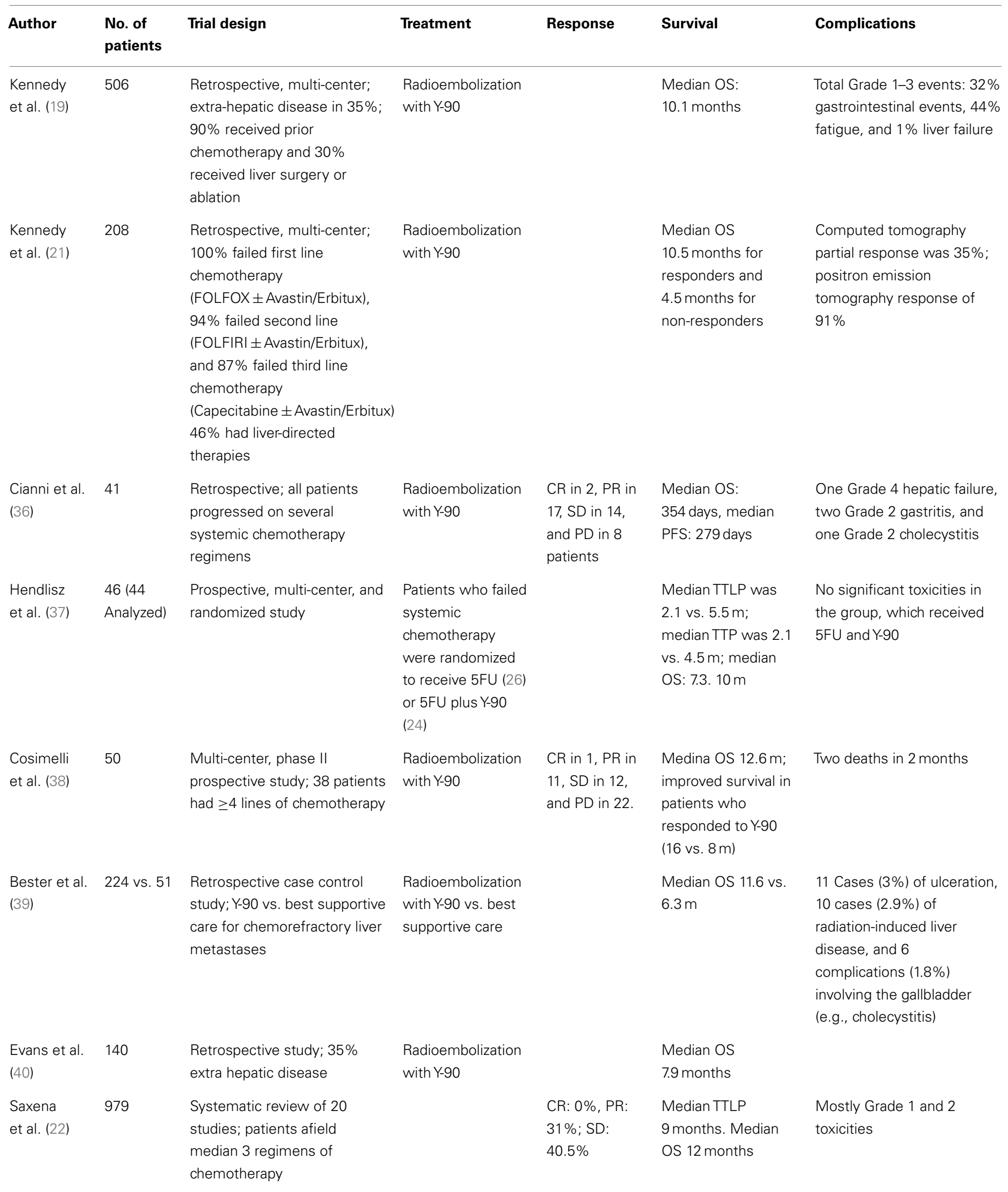

$C R$, complete response; $P R$, partial response; $S D$, stable disease; $P D$, progressive disease; $P F S$, progression free survival; EHD, extra-hepatic disease; ORR, objective response rate; OS, overall survival; CEA, carcinoembryonic antigen; TTP, time to progression; TTLP, time to progression in the liver; HAC, hepatic arterial chemoinfusion. 
survival was significantly better in patients with no extra-hepatic disease (37.8 vs. $13.4 \mathrm{~m}$ ). This study is limited by small number (only 19 patients), retrospective nature, and varied chemotherapy regimens used.

In summary, Y-90 therapy in combination with first line chemotherapy is safe and may improve tumor response rates. Although a trend toward improved overall survival is reported, more data is required to establish its role in improving overall survival outcomes. There are a few large ongoing clinical studies (SIRFLOX trial:NCT00724503 and FOXFIRE trial:ISRCTN83867919) that include current standard of care chemotherapy regimens (with biological agents) with Y-90 and may help establish the benefit of Y-90 as part of first line therapy.

\section{YTTRIUM-9O RADIOEMBOLIZATION IN COMBINATION WITH SECOND- OR THIRD-LINE CHEMOTHERAPY}

Van Hazel et al. reported results of concomitant therapy of Y-90 radioembolization with systemic irinotecan in patients who failed initial 5-FU chemotherapy (Table 3) (34). Irinotecan was administered to assess maximum tolerated dose. In a group of 25 patients, 11 (48\%) patients had PR and 9 (39\%) had stable disease (SD). The median overall survival was 12.2 months. Grade 3-4 toxicities occurred in $12(48 \%)$ patients.

In another study, Lim et al. reported results from a heterogeneous group of patients $(n=30)$ who were treated with 5 -FU as first line chemotherapy (Table 3) (35). Eight of these patients failed 5-FU, 14 patients failed 5-FU and subsequent oxaliplatin and irinotecan, and 8 patients failed 5-FU and subsequent oxaliplatin or irinotecan. Thirty-three percent had PR and TTP was 5.3 months. There was $13 \%$ incidence of duodenal/gastric ulcers from non-target embolization of Yttrium-90 microspheres.

\section{YTTRIUM-90 RADIOEMBOLIZATION AS A SALVAGE TREATMENT FOR CHEMOTHERAPY-REFRACTORY DISEASE}

Multiple retrospective studies reported outcomes when Y-90 was used as salvage therapy in chemorefractory patients (Table 4) $(19,21,22,36-40)$. Bester et al. reported the results of a retrospective study to evaluate the safety and survival of patient with chemotherapy-refractory metastatic CRC to the liver treated with resin microsphere Y-90 $(n=224)$ compared with patients who underwent standard/supportive care $(n=51)$ (Table 4) (39). The median overall survival after radioembolization was 11.9 months compared to 6.3 months for the standard care cohort. The incidence of duodenal/gastric ulceration was 3.2\%.

In a phase II multi-centered clinical trial for chemotherapyrefractory colorectal liver metastasis, Cosimelli reported an overall response rate of $24 \%$ using the RECIST criteria (38). The median time to progression was 3.7 months and the median overall survival was 12.6 months. Apart from two deaths at 40 days (from renal failure) and 60 days (liver failure) after treatment, all of their adverse events were classified within the WHO Grade 1/2 category. Two patients from their cohort were downsized with radioembolization to enable potential curative resection.

A recent systematic review by Saxena et al. $(n=979)$ reported a median time to intrahepatic progression of 9 months and a median overall survival of 12 months, the overall acute toxicities ranged from 11 to $100 \%$ (median $41 \%$ ) with most of the cases being mild - Grade 1/2 (median 39\%), which resolved without intervention (22).

Overall, median survival is in the range of 10-12 months in these studies. The response rates are at 31\% PR and $41 \% \mathrm{SD}$ (22). Presence of large volume disease ( $>25 \%$ of liver volume), extra-hepatic disease, poor response to Y-90, and $\geq 3$ lines of prior chemotherapy portend poor prognosis (22). Given that the median survival of patients who failed third line chemotherapy is in the range of 4-6 months, therapy with Y-90 may improve survival outcomes. The utility of concomitant chemotherapy needs to be further explored.

\section{RECOMMENDATIONS}

Yttrium-90 therapy is recommended for chemorefractory patients with liver-only or liver-predominant disease and in patients who do not wish to have systemic chemotherapy. Use of Y-90 therapy in conjunction with standard first line or second line chemotherapy requires more rigorous data and is recommended in a clinical trial setting. The use of Y-90 is not recommended in patients with extensive extra-hepatic disease or extensive bilobar hepatic involvement. Similarly, patients with poor performance status (ECOG PS > 2) are not suitable for Y-90 therapy.

\section{CONCLUSION}

Yttrium-90 microsphere therapy is being increasingly used for treatment of colorectal metastases to the liver. Patients who have failed systemic chemotherapy appear to benefit from this therapy. Concurrent use of Y-90 in first and second line chemotherapy is currently being investigated. Future trials need to focus on identifying specific target populations who may benefit most from this therapy.

\section{REFERENCES}

1. Siegel R, Naishadham D, Jernal A. Cancer statistics, 2012. CA Cancer J Clin (2012) 62:10-29. doi:10.3322/caac.21149

2. Chong G, Cunningham D. Improving long-term outcomes for patients with liver metastases from colorectal cancer. J Clin Oncol (2005) 23:9063-6. doi:10. 1200/JCO.2005.04.4669

3. Cummings LC, Payes JD, Cooper GS. Survival after hepatic resection in metastatic colorectal cancer: a population-based study. Cancer (2007) 109:718-26. doi: $10.1002 /$ cncr. 22448

4. Rees M, Tekkis PP, Welsh FK, O’Rourke T, John TG. Evaluation of long-term survival after hepatic resection for metastatic colorectal cancer: a multifactorial model of 929 patients. Ann Surg (2008) 247:125-35. doi:10.1097/SLA. 0b013e31815aa2c2

5. Morris EJ, Forman D, Thomas JD, Quirke P, Taylor EF, Fairley L, et al. Surgical management and outcomes of colorectal cancer liver metastases. Br J Surg (2010) 97:1110-8. doi:10.1002/bjs.7032

6. National Comprehensive Cancer Network Guidelines, Rectal Cancer Treatment Guidelines. National Comprehensive Cancer Network (NCCN) (2013). Available from: http://www.nccn.org/professionals/physician_gls/f_guidelines.asp\#rectal

7. Scheithauer W, Rosen H, Kornek GV, Sebesta C, Depisch D. Randomised comparison of combination chemotherapy plus supportive care with supportive care alone in patients with metastatic colorectal cancer. BMJ (1993) 306:752-5. doi:10.1136/bmj.306.6880.752

8. Nordic Gastrointestinal Tumor Adjuvant Therapy Group. Expectancy or primary chemotherapy in patients with advanced asymptomatic colorectal cancer: a randomized trial. J Clin Oncol (1992) 10:904-11.

9. Simmonds PC. Palliative chemotherapy for advanced colorectal cancer: Systematic review and meta-analysis. Colorectal Cancer Collaborative Group. BMJ (2000) 321:531-5. doi:10.1136/bmj.321.7260.531 
10. Barber FD, Mavligit G, Kurzrock R. Hepatic arterial infusion chemotherapy for metastatic colorectal cancer: a concise overview. Cancer Treat Rev (2004) 30:425-36. doi:10.1016/j.ctrv.2004.04.002

11. Kemeny NE, Niedzwiecki D, Hollis DR, Lenz HJ, Warren RS, Naughton MJ, et al. Hepatic arterial infusion versus systemic therapy for hepatic metastases from colorectal cancer: a randomized trial of efficacy, quality of life, and molecular markers (CALGB 9481). J Clin Oncol (2006) 24:1395-403. doi:10.1200/JCO.2005.03.8166

12. Breedis C, Young G. The blood supply of neoplasms in the liver. Am J Pathol (1954) 30:969-77.

13. Chen HS, Gross JF. Intra-arterial infusion of anticancer drugs: theoretic aspects of drug delivery and review of responses. Cancer Treat Rep (1980) 64:31-40.

14. Kalva SP, Thabet A, Wicky S. Recent advances in transarterial therapy of primary and secondary liver malignancies. Radiographics (2008) 28:101-17. doi:10.1148/rg.281075115

15. Lien WM, Ackerman NB. The blood supply of experimental liver metastases. II. A microcirculatory study of the normal and tumor vessels of the liver with the use of perfused silicone rubber. Surgery (1970) 68:334-40.

16. Ariel IM. Treatment of inoperable primary pancreatic and liver cancer by the intra-arterial administration of radioactive isotopes (Y90 radiating microspheres). Ann Surg (1965) 162:267-78. doi:10.1097/00000658-196508000-00018

17. Gulec SA, Fong Y. Yttrium 90 microsphere selective internal radiation treatment of hepatic colorectal metastases. Arch Surg (2007) 142:675-82. doi:10.1001/ archsurg.142.7.675

18. FDA Guidelines on Use of Microsphere Treatment for Colorectal Metastasis Disease to the Liver (2013). Available from: http://www.accessdata.fda. gov/cdrh_docs/pdf/p990065a.pdf; http://www.accessdata.fda.gov/cdrh_docs/ pdf/H980006b.pdf

19. Kennedy AS, Ball D, Cohen SJ, Cohn M, Coldwell DM, Drooz A, et al. U.S. patients receiving resin $90 \mathrm{Y}$ microspheres for unresectable colorectal liver metastases: a multicenter study of 506 patients. J Clin Oncol (2012) 30: abstr3590.

20. Murthy R, Nunez R, Szklaruk F, Erwin W, Madoff DC, Gupta S, et al. Yttrium90 microsphere therapy for hepatic malignancy: devices, indications, technical considerations, and potential complications. Radiographics (2005) 25:S41-55. doi:10.1148/rg.25si055515

21. Kennedy AS, Coldwell D, Nutting C, Murthy R, Wertman DE Jr, Loehr SP, et al. Resin 90Y-microsphere brachytherapy for unresectable colorectal liver metastases: modern USA experience. Int J Radiat Oncol Biol Phys (2006) 65:412-25. doi:10.1016/j.ijrobp.2005.12.051

22. Saxena A, Bester L, Shan L, Perera M, Gibbs P, Meteling B, et al. A systematic review on the safety and efficacy of Yttrium-90 radioembolization for unresectable, chemorefractory colorectal cancer liver metastases. J Cancer Res Clin Oncol (2014) 140:537-47. doi:10.1007/s00432-013-1564-4

23. Szyszko T, Al-Nahhas A, Canelo R, Habib N, Jiao L, Wasan H, et al. Assessment of response to treatment of unresectable liver tumours with $90 \mathrm{Y}$ microspheres: value of FDG PET versus computed tomography. Nucl Med Commun (2007) 28:15-20. doi:10.1097/MNM.0b013e328011453b

24. Tochetto SM, Rezai P, Rezvani M, Nikolaidis P, Berggruen S, Atassi B, et al. Does multidetector CT attenuation change in colon cancer liver metastases treated with 90Y help predict metabolic activity at FDG PET? Radiology (2010) 255:164-72. doi:10.1148/radiol.09091028

25. Gulec SA, Suthar RR, Barot TC, Pennington K. The prognostic value of functional tumor volume and total lesion glycolysis in patients with colorectal cancer liver metastases undergoing $90 \mathrm{Y}$ selective internal radiation therapy plus chemotherapy. Eur J Nucl Med Mol Imaging (2011) 38:1289-95. doi:10.1007/s00259-011-1758-4

26. Dancey JE, Shepherd FA, Paul K, Sniderman KW, Houle S, Gabrys J, et al. Treatment of nonresectable hepatocellular carcinoma with intrahepatic $90 \mathrm{Y}-$ microspheres. J Nucl Med (2000) 41:1673-81.

27. Naymagon S, Warner RR, Patel K, Harpaz N, Machac J, Weintraub JL, et al. Gastroduodenal ulceration associated with radioembolization for the treatment of hepatic tumors: an institutional experience and review of the literature. Dig Dis Sci (2010) 55:2450-8. doi:10.1007/s10620-010-1156-y

28. Yip D, Allen R, Ashton C, Jain S. Radiation-induced ulceration of the stomach secondary to hepatic embolization with radioactive Yttrium microspheres in the treatment of metastatic colon cancer. J Gastroenterol Hepatol (2004) 19:347-9. doi:10.1111/j.1440-1746.2003.03322.x
29. Gray BN, Burton MA, Kelleher D, Klemp P, Matz L. Tolerance of the liver to the effects of Yttrium-90 radiation. Int J Radiat Oncol Biol Phys (1990) 18:619-23. doi:10.1016/0360-3016(90)90069-V

30. Gray B, Van Hazel G, Hope M, Burton M, Moroz P, Anderson J, et al. Randomised trial of SIR-spheres plus chemotherapy vs. chemotherapy alone for treating patients with liver metastases from primary large bowel cancer. Ann Oncol (2001) 12:1711-20. doi:10.1023/A:1013569329846

31. Van Hazel G, Blackwell A, Anderson J, Price D, Moroz P, Bower G, et al. Randomised phase 2 trial of SIR-spheres plus fluorouracil/leucovorin chemotherapy versus fluorouracil/leucovorin chemotherapy alone in advanced colorectal cancer. J Surg Oncol (2004) 88:78-85. doi:10.1002/jso.20141

32. Sharma RA, Van Hazel GA, Morgan B, Berry DP, Blanshard K, Price D, et al. Radioembolization of liver metastases from colorectal cancer using Yttrium-90 microspheres with concomitant systemic oxaliplatin, fluorouracil and leucovorin chemotherapy. J Clin Oncol (2007) 25:1099-106. doi:10.1200/JCO.2006.08. 7916

33. Kosmider S, Tan TH, Yip D, Dowling R, Lichtenstein M, Gibbs P. Radioembolization in combination with systemic chemotherapy as first-line therapy for liver metastases from colorectal cancer. J Vasc Interv Radiol (2011) 22:780-6. doi:10.1016/j.jvir.2011.02.023

34. Van Hazel GA, Pavlakis N, Goldstein D, Olver IN, Tapner MJ, Price D, et al. Treatment of fluorouracil-refractory patients with liver metastases from colorectal cancer by using Yttrium-90 resin microspheres plus concomitant systemic irinotecan chemotherapy. J Clin Oncol (2009) 27:4089-95. doi:10.1200/ JCO.2008.20.8116

35. Lim L, Gibbs P, Yip D, Shapiro JD, Dowling R, Smith D, et al. A prospective evaluation of treatment with selective internal radiation therapy (SIRspheres) in patients with unresectable liver metastases from colorectal cancer previously treated with 5-FU based chemotherapy. BMC Cancer (2005) 5:132. doi:10.1186/1471-2407-5-132

36. Cianni R, Urigo C, Notarianni E, Saltarelli A, Salvatori R, Pasqualini V, et al. Selective internal radiation therapy with SIR-spheres for the treatment of unresectable colorectal hepatic metastases. Cardiovasc Intervent Radiol (2009) 32:1179-86. doi:10.1007/s00270-009-9658-8

37. Hendlisz A, Van den Eynde M, Peeters M, Maleux G, Lambert B, Vannoote J, et al. Phase III trial comparing protracted intravenous fluorouracil infusion alone or with Yttrium-90 resin microspheres radioembolization for liver-limited metastatic colorectal cancer refractory to standard chemotherapy. J Clin Oncol (2010) 28:3687-94. doi:10.1200/JCO.2010.28.5643

38. Cosimelli M, Golfieri R, Cagol PP, Carpanese L, Sciuto R, Maini CL, et al. Multicentre phase II clinical trial of Yttrium-90 resin microspheres alone in unresectable, chemotherapy refractory colorectal liver metastases. Br J Cancer (2010) 27(103):324-31. doi:10.1038/sj.bjc.6605770

39. Bester L, Meteling B, Pocock N, Pavlakis N, Chua TC, Saxena A, et al. Radioembolization versus standard care of hepatic metastases: comparative retrospective cohort study of survival outcomes and adverse events in salvage patients. J Vasc Interv Radiol (2012) 23:96-105. doi:10.1016/j.jvir.2011.09.028

40. Evans KA, Richardson MG, Pavlakis N, Morris DL, Liauw W, Bester L. Survival outcomes of a salvage patient population after radioembolization of hepatic metastases with Yttrium-90 microspheres. J Vasc Interv Radiol (2010) 21:1521-6. doi:10.1016/j.jvir.2010.06.018

Conflict of Interest Statement: The authors declare that the research was conducted in the absence of any commercial or financial relationships that could be construed as a potential conflict of interest.

Received: 29 January 2014; accepted: 09 May 2014; published online: 25 July 2014. Citation: Raval M, Bande D, Pillai AK, Blaszkowsky LS, Ganguli S, Beg MS and Kalva SP (2014) Yttrium-90 radioembolization of hepatic metastases from colorectal cancer. Front. Oncol. 4:120. doi: 10.3389/fonc.2014.00120

This article was submitted to Cancer Imaging and Diagnosis, a section of the journal Frontiers in Oncology.

Copyright (C) 2014 Raval, Bande, Pillai, Blaszkowsky, Ganguli, Beg and Kalva. This is an open-access article distributed under the terms of the Creative Commons Attribution License (CC BY). The use, distribution or reproduction in other forums is permitted, provided the original author(s) or licensor are credited and that the original publication in this journal is cited, in accordance with accepted academic practice. No use, distribution or reproduction is permitted which does not comply with these terms. 